\title{
A University-industry knowledge transfer online education approach via a cloud- based database global solution
}

\author{
Emmanouil Tzavidas, Peter Enevoldsen and George Xydis ${ }^{*}$ (i)
}

\author{
* Correspondence: gxydis@btech.au. \\ Department of Business \\ Development and Technology, \\ Aarhus University, Birk Centerpark \\ 15, 7400 Herning, Denmark
}

\begin{abstract}
Knowledge sharing between different types of organisations, in this case the University-Industry (U-I) relation, contains barriers related to the differentiation of structure and purpose for each organisation. Both the university and industry have to make sure that they have access to data and information. This accessibility enables the value-added process of transforming data into knowledge. The purpose of this paper is the analysis of $\mathrm{U}-\mathrm{I}$ cooperation- especially under the new online requirements - an illustration of how the knowledge is created and shared in the organisation based on the socialisation, externalisation, combination, and internalisation (SECI) model and how this is aligned to the value proposition. As a knowledge management example case, a database for the Centre for Energy Technologies of Aarhus University was developed that will overtime help the university to increase its value proposition and be the heart of knowledge exchange with the industry in an organised way. The value of this work is intended to pave the way in building structured working relations between the industry and academia, facilitating the means in order to achieve a higher degree of overall efficiency.

Keywords: Data architecture, Knowledge sharing, SECI model, Value proposition, University-industry collaboration, Engineering education
\end{abstract}

\section{Introduction}

Collaboration between University and Industry exists for more than 100 years. In a knowledge-based economy, this interplay and the outcomes of the particular type of cooperation considered to be significant for both sides (Edmondson, Valigra, Kenward, Hudson, \& Belfield, 2012). University and industry are organisations that despite their differences in structure and actions, they both use knowledge to achieve their goals, either creating and share new knowledge or gain financial profit. They can establish a research-based partnership that focus on the development of new products (tangible or intangible) or test products that already exist.

Although this collaboration is very profitable for both sides, it faces some barriers that require detailed coordination and proper communication. These barriers occur

(c) The Author(s). 2020 Open Access This article is licensed under a Creative Commons Attribution 4.0 International License, which permits use, sharing, adaptation, distribution and reproduction in any medium or format, as long as you give appropriate credit to the original author(s) and the source, provide a link to the Creative Commons licence, and indicate if changes were made. The images or other third party material in this article are included in the article's Creative Commons licence, unless indicated otherwise in a credit line to the material. If material is not included in the article's Creative Commons licence and your intended use is not permitted by statutory regulation or exceeds the permitted use, you will need to obtain permission directly from the copyright holder. To view a copy of this licence, visit http://creativecommons.org/licenses/by/4.0/. 
mainly because these organisations use, create or acquire knowledge that is not aligned with each other. Another important feature that is related with the differentiation of the goals of these two organisations is that Universities are more interested in topics and projects that their community find interesting to examine, while Industry tends to develop projects and solve problems that are valuable to their customers (Rosenberg \& Nelson, 1994).

Knowledge transfer is an internal process which is been implemented within the environment of the organisation. As a result, every external knowledge that is new to the organisation require competencies that will ensure the acquisition, storage and re-use of the new knowledge (Gilbert \& Cordey-Hayes, 1996). Knowledge creation is illustrated through the SECI model of Nonaka and Takeuchi (1995), where they implemented a four-step process that explains how tacit and explicit knowledge is converted into organisational knowledge and transferred within the environment of the organisation. This iterative process is continuously creating, re-use and diffuse the knowledge in the organisation increasing its value. University and Industry have different motives that enable them to develop this collaboration (Dang, Jasovska, Gulzar Rammal, \& Schlenker, 2019; Robertson, McCarthy, \& Pitt, 2019; Thomas \& Paul, 2019).

Each organisation perceive value and value proposition in a different way according to its orientation, purpose and structure (Nielsen \& Sort, 2013). On one hand, university creates new knowledge and share it through teaching and research-based activities. On the other hand, industry captures, creates or reproduces knowledge and shares it in most cases strictly within its environment in order to achieve profit and viability on the long term (Dasgupta \& Paul, 1994). What has been lately gaining attention over the last decades is research and development $(R \& D)$ departments within companies that create new knowledge, without necessarily having developed the mindset of sharing this knowledge, which influences radically innovation (Knudsen, 2007). A number of precautions are often taken, such as confidentiality agreements, sharing constraints and strictly classified outputs belonging to the specific departments of the companies (Tourangeau, 2018). Thousands of researchers produce results and use their company's affiliation - and only that (Jørgensen, Tambo, \& Xydis, 2019; Xydis \& Mihet-Popa, 2017). This approach has created no-share mentalities and confidential research works that will never be shared, some of which could have been inspiring or the starting point for other researchers in some other part of the world in industry or academia (Czarnitzki, Grimpe, \& Pellens, 2015).

Knowledge, which is on the top of the pyramid and the outcome of the adding value process of transforming data into information, can be also optimised by using Information Technology (IT). Even the usage of social media it has been proven that it plays a crucial role in knowledge creation in the university (Saide, Indrajit, Trialih, Ramadhani, \& Najamuddin, 2019). IT contains tools such as database management systems, which can effectively create databases where data are stored, processed, categorised and finally enable the user to understand and gather experience and knowledge. This work comes to propose a technology-based solution to confront the no-share matter. It introduces a database that Centre for Energy Technologies (CET) of Aarhus University will use in the future where each user will have specific rights according to the agreements between the industry and the university aiming at registering information and research projects mapping the knowledge proposing a global solution of a Cloud-based database, 
adding to the online education model for engineers which gains more and more attention. The remainder of this paper includes five more sections. The literature review part, where various approaches on knowledge sharing are presented, the methodology, the business model canvas of the university, the technical infrastructure, which in this case is the CET database constructed and the conclusions section.

\section{Literature review}

Well-known theories related to knowledge management were analysed for the specific paper, focused on the importance of collaboration, the benefits for each side and their goals. Then the SECI model of Nonaka is presented which describe the iterative process of organisational knowledge transfer and creation. Lastly, they are mentioned important barriers in the knowledge transfer that occur in an organisation.

Collaboration types and practices between University-Industry (U-I) have been increased since the 1980s. It has been mentioned that these partnerships started to focus on pure exchange of knowledge, co-invention of patents and R\&D projects (Levy, Roux, \& Wolff, 2007). From the perspective of the industry, this collaboration is considered to be as a very important link that is directly connected with consultancy and joint research (Cohen, Nelson, \& Walsh, 2002) based on fundamental dimensions for successful collaborative relationships (Schiuma \& Carlucci, 2018). If the partnership between $\mathrm{U}-\mathrm{I}$ is successfully established and stable regarding knowledge-transfer and coordination, both participants can benefit in various sectors. The data from academia can be utilised to build new ideas (Xydis, Pechlivanoglou, \& Nayeri, 2015), proof of concepts (Papadopoulou, Alasis, \& Xydis, 2019), and eventually products (Koscis \& Xydis, 2019). According to Lee (2000), each participant must fulfil the requirements and needs of the other in order to maintain this profitable collaboration and both of them achieve their goals. The main reasons for a collaboration from the perspective of the University are related to finding practical problems in the industry that can be solved and taught in courses, creating job opportunities easily accessed for research assistants, students and graduates with lab experiments, extended research, internships and jobs, testing the applicability of the theories and knowledge in the demanding and dynamic environment of the industry and finally gaining knowledge by researching in a new product (tangible or intangible) or problem that needs a solution. One of the final scopes is to teach based on entrepreneurial learning processes since this way students start to think and act as entrepreneurs as early as possible and perform relevant projects in knowledgeintensive Small and medium-sized enterprise (SME) environment (Secundo et al., 2017). Students learn to survive (if not to thrive) in a multiple stakeholder environment inside the university network (Secundo, Dumay, Schiuma, \& Passiante, 2016). On the other side, the industry is aiming to use the external knowledge in order to create new products, re-design the conformation of a specific sector or process to achieve improved product/service quality, assure that it has access to new knowledge by hiring well-educated graduates and get access to new technology and become more innovative by inventing in an $R \& D$ partnership. What is proven to be crucial for future collaboration, is mutual trust, which today is questionable. Oliver, Montgomery, and Barda (2019) identified two levels of trust; organisational and individual.

According to Nonaka and Konno (1998), knowledge is categorised into tacit and explicit. Tacit knowledge is not easy to be explained and diffused because it is based on 
the individual's experiences and beliefs, personal work and practice. Tacit knowledge is categorised into technical and cognitive dimension. Technical dimension refers to the individual's capabilities acquired by doing and practising and are described as personal skills. Cognitive dimension describes the beliefs, individual's way of thinking, values that are deeply-rooted in every person in an organisation (Koedinger, Corbett, \& Perfetti, 2012). They are difficult to describe and it is the knowledge influencing the most the perception the individual has about the world. According to Howells (1995) "it appears that tacit is not forever tacit and with effort, it can be partially formalised and partially communicated". Explicit knowledge is easily quantitively and qualitatively depicted. It is in the hand of an organisation to share it with different forms like data, scientific paper, computer applications and manuals that are easily accessible by individuals. According to Zhang (2017), organisations have to seek explicit knowledge in every type of document and for tacit knowledge from individuals that have the proper skills in the organisation. Explicit knowledge can be easily accessed and transferred between individuals while tacit knowledge can only be diffused between knowledge holders. Yusuf (2008) stresses that commercialisation and knowledge sharing is crucial when the knowledge is either uncodified or tacit. Restrictions on open knowledge sharing do have a negative impact in innovation, business creation, and eventually confronting societal challenges. It was found in a literature based study in China for instance, that output and behaviour control practices influence negatively the cooperation performance between U-I (Xu, Zhou, Xu, \& Li, 2014). In the case of a collaboration with an industrial partner, the university's researchers will have the opportunity to work together and cooperate. By doing this, it is easier to share their tacit knowledge, building trust Oliver et al. (2019) and socializing through observation and discussion (Castelfranchi, 2004). By adopting a multi-disciplinary observation based perspective, the complexities of how organisations convert knowledge to a long-lasting advantage can be tackled (Moustaghfir, Schiuma, Moustaghfir, Schiuma, \& Schiuma, 2013).

Externalisation refers to the process of converting tacit into explicit knowledge. During this step, knowledge is captured and codified into documents, databases, images. This crystallisation enables and supports the diffusion of knowledge between individuals in the organisation. An important key aspect of this process is the metaphor, which is a simple way of understanding a concept by using a comparison to another concept or an idea. Barnes, Pashby, and Gibbons (2002) referred to the formalisation of processes and interactions as a success factor that improved the knowledge creation and diffusion, while Lerro, Iacobone, and Schiuma (2012) focused onto intelligent and agile organisations in order to achieve new development paths. That occurs because any researcher of the organisation can get advises from previous projects regarding a specific process or experiment that is useful in another project or can take part later at the specific project and acquire the required knowledge in order to successfully contribute and be adapted in the team.

The combination is the phase where the explicit knowledge is converted into a more complex form. While the type of knowledge is the same, its structure is a combination or sets of explicit knowledge. This result occurs because of the exchange, combination and integration of knowledge between individuals through documents, e-mails, meetings or other tools that are supported by Information and Communication Technology. In practice, combination is the outcome of three steps. The first step is the collection 
and combination of externalised knowledge such as public data, while the collection of this knowledge can take place inside or outside of the organisation. Then, the diffusion of the explicit knowledge between individuals in the organisation is supported by presentations and meetings ensuring the creation of new knowledge. Ultimately, the editing and processing part of explicit knowledge like reports, plans and market data leads to a more usable and accessible explicit knowledge. Combination exists in research (university) when scientists cite each other works or when researchers are writing a paper based on a project that is the outcome of a collaboration between U-I. According to Hermans and Castiaux (2006), this part of knowledge spiral supports the arrangement of new meetings between researchers in order to further discuss the technical aspects of the report. In these meetings, new tacit knowledge can be shared.

The process of internalisation refers to the conversion of explicit knowledge into tacit and is described by Nonaka, Takeuchi, and Umemoto (1996) as "learning by doing". This process is accomplished if individuals in the organisation apply methods or concepts that already exist in organisation's documents or databases and if they experiment or run simulations during their work time or during collaborations. Based on a study, it was proven that knowledge-intensive business services companies (from the UK and US) engaged in a doing-using-interacting mode of organisational learning, had an active and intense collaboration with universities for innovation (Lee et al., 2019). Projects that are based on collaboration between U-I enable the researchers of the University to build relationships and the possibility of a future collaboration between them on more fundamental issues (Burnside et al., 2008; Hermans \& Castiaux, 2006; Kauppila, Mursula, Harkonen, \& Kujala, 2015).

Knowledge transfer differs from other types of transactions because it depends on an equal exchange so both participants benefit approximately with the same way. It is considered, like knowledge management, as an internal process which is based on the process of knowledge by using skills inside the organisation that will contribute positively and increase the overall outcome quality (Amesse \& Cohendet, 2001). Looking at the case of U-I relationship, projects are developed based on this cooperation. There, knowledge is flowing from a source that is outside of the environment of the organisation and the development of activities are related with the acceptance of the new knowledge, the diffusion and the assimilation of it by all the individuals that are involved on the project is critical (Gilbert \& Cordey-Hayes, 1996). According to Etzkowitz \& Leydesdorff, (2000), the source of knowledge creation in an organisation which has an educational and research purpose like University is in the three main functions of it: Through courses and every action that has as a goal the education of the individuals in the organisation, the development of research work which is related with laboratories, scientific papers and R\&D and finally, their presence in social and economic development. Chatterjee's (2014) definition about knowledge sharing is the competences of individual and collective learning. On the one hand, individuals gather skills and abilities by doing their work or training. On the other hand, Collective learning refers to the whole organisation's communities of practice.

Universities can be positively affected by knowledge management in ways that are related to the industry collaboration, better researchers' and students' learning and finally reducing the costs of its operational activities. It is necessary for the University to establish the knowledge transfer between individuals and confront the factors that slow 
down this process (Killingsworth, Xue, \& Liu, 2016). In order to overcome the obstacles in knowledge transfer and increases its performance, the organisation has to find, identify and disable the factors that create bottlenecks and limitations in the flow of knowledge (Chatterjee, 2014). Han (2017) focused on knowledge sharing between U-I when it comes to patent creation. It was proven by an analysis in 263 SMEs in a region in South Korea that industry influences negatively patent applications. It is important to stress that it is not only when companies are involved that knowledge sharing is dropping. It is a huge issue in academic institutions. Kumaraswamy et al. (2012) pointed out that there are factors that have a negative impact in collaborative knowledge sharing culture also in an academic institute. According to Nychis, Sekar, Andersen, Kim, and Zhang (2008), knowledge sharing is affected the most by three different aspects in an organisation. These aspects are culture, management and technology and they are directly related to higher costs and lower income. According to Riege (2005), knowledge management and diffusion have to be adapted in the culture of the organisation instead of changing the culture to fulfil the requirements needed for effective knowledge management. Bottlenecks can also show up when the organisation is not making proper use of the technology. That happens when there is unsuitable technology, not effective training and information or when the individuals are not willing to use the technology properly. Kukko and Helander (2012) state that in inter-organisational knowledge transfer like project collaboration uncertainty and equivocality are the main reasons of slow knowledge transfer. Uncertainty is the lack of information that the one or both of the collaborators are missing and are necessary to accomplish a task as part of the project (Anatan, 2018). In order to bridge the gap, each participant has to gather the relevant data and information so the required knowledge can be produced (Galbraith, 1977). Equivocality refers to the misunderstanding of the current information each organisation acquires. According to Daft and Weick (1984), multiple and confusing interpretations that exist in the organisation are refined as ambiguity.

\section{Methodology}

An analysis was conducted on the technical infrastructure of the organisation. Literature review has been favourable to test the hypothesis of the specific papers, ensuring representable data of U-I collaborations, the correlation of knowledge management and the value proposition of the University.

Qualitative, deductive research was conducted to test the hypothesis that SECI Model of Nonaka can be applied to map the knowledge creation and diffusion, which increases the value proposition of Universities and that the use of IT can benefit knowledge management.

The hypothesis formulated in order to answer the following research questions:

- How the University can capture and diffuse effectively this knowledge in its environment.

- Why knowledge creation and diffusion are important for potential cooperation with the Industry.

- Why and how IT can reinforce knowledge creation and transfer (via an online learning environment). 
The main outcome of the deductive research was the visualisation of knowledge creation and transfer in the University, the role of IT in these processes and the direct impact knowledge management has on the value proposition of the organisation. Figure 1 presents the methodology followed in a flowchart.

\section{The business model canvas of the university}

In order for the organisation to be able to involve in any kind of external knowledge interactions, add new knowledge in its environment and gather funds for research that will contribute in knowledge creation and sharing, it is crucial to have a clear picture and understanding of the value creation process. In their work on U-I collaborations, Hadăr, Marin, Costoiu, Boanță, and Cișmașu (2016) and Nielsen and Sort (2013) have used the Business Model Canvas to analyse the collaboration of the University-Industry and how the value is created and supported (Fig. 2).

\section{Key partnerships}

Organisations are seeking for alliances in order to benefit, sustain competitiveness and gain external resources. In the case of U-I, this partnership is a joint venture that its main purpose is to create value for each participant. University as an organisation may have several key partnerships. The government sector (research funding) and external researchers (a collaboration between different universities and industrial partners) are not directly related but can be aligned with the strategic goals of the University to build a proper relationship with the industry.

\section{Key activities}

The actions that are illustrated to this block are the most valuable for the business model, in order to achieve high performance. Key activities are directly connected with customer relationships and value proposition. Research is a key aspect of the University as an educational organisation and a module that quantifies the performance and increases the prestige of the University (Lynn, Reddy \& Aram, 1996). Research and publication of academic research is also an illustration related to the knowledge that exists in an organisation and the scientific sectors that are focused on. When the university is in a joint venture, its activities can vary. It is possible to participate in the design of a product that the industrial partner will produce or to act as an external consultant that assists a company to train its employees in order to increase its performance.

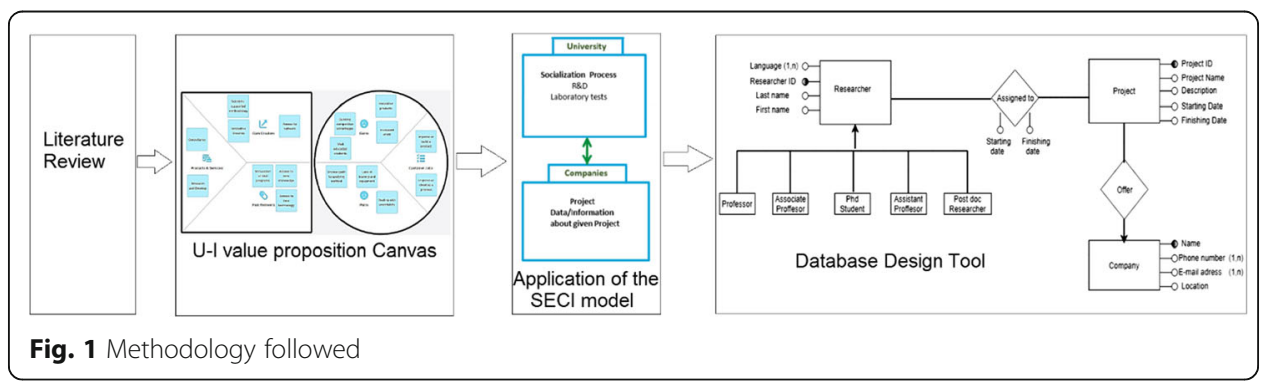




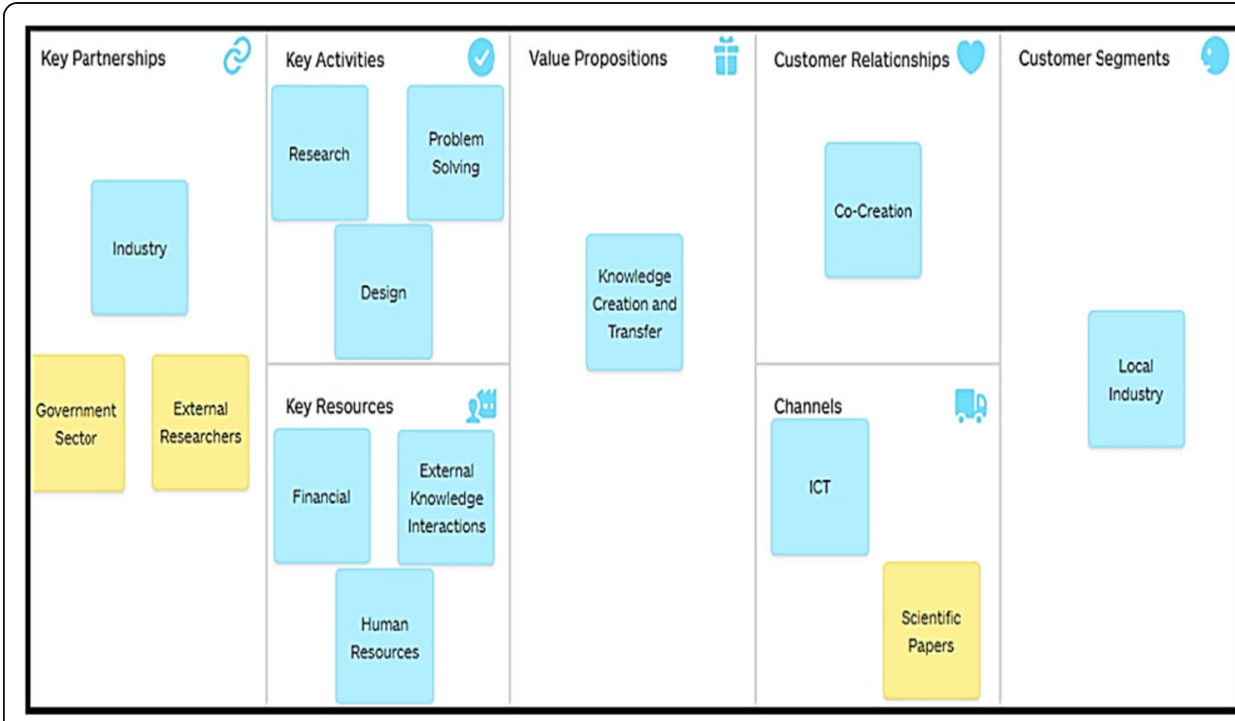

Fig. 2 The Business Model Canvas of the University in U-I collaboration

\section{Key resources}

Key resources refer to the assets that an organisation must obtain in order to develop its business model. Financial resources are crucial because they support the operation and the research that is conducted in the university. External knowledge interactions with Industrial partner allows the university to create new knowledge and gain insight into practical problems that are worth teaching (Lee, 2000). Experienced and welleducated researchers can add and produce new knowledge, which will contribute to the overall value that is offered by the university.

\section{Customer relationships}

The particular block demonstrates the structure of the relationship the organisation has with its customer. From the university's perspective, an Industrial partner can be taken into account as a customer because it is usually funding the research that the University conducts in order to apply its knowledge. University creates new knowledge that can be shared through its organisation and the industrial partner/customer creates value that is used for profit. As a result, they collaborate to co-create value for each other.

\section{Communication channels}

Organisations make use of channels in order to illustrate their area of expertise, inform the customers so they can evaluate the University's Value Proposition and create a touch point with the customer in order to arrange and proceed to the purchase of a product/service. With various tools such as databases, website development, every project of the university can be presented along with the academic and professional background and $\mathrm{CV}$ of the researchers that worked on the project. Other tools like e-mails and Voice over Internet Protocol meetings can be used for knowledge diffusion. For example, partners can arrange online meetings for further discussion of the project or send report files related to the progress of the research. Databases can be used as 
technical infrastructure of knowledge creation because they can contain data and information of an old project that will be the base for future research of the university.

\section{Customer segments}

Customer segments block refers to the customers that the organisation is interested in. The University has to analyse their interests, compare them with the needs of the potential customer and finally establish a cooperation that will benefit both the university and the customer. CET in Aarhus University is focused in the areas of renewable energy, energy demand, electricity markets, and hydrogen among others. As a result, the centre cooperates with companies that have interests that are aligned with theirs like new and innovative energy systems.

\section{The value proposition and IT as a technical infrastructure (CET database)}

Value proposition is characterised by a set of tangible or intangible products and services with specific attributes that have as a purpose to satisfy the customers' needs. These products or benefits can vary from organisation to organisation, depending on the different orientation, structure and characteristics. Some of them can be innovative while others are similar to existing products with added characteristics.

The value proposition of the university is based on knowledge creation and diffusion. While the size of the company should be taken into account when evaluating the needs of the industrial partner, new knowledge is a common feature that exists in the agenda of every company (Osterwalder, 2010). Small startups and medium enterprises focusing more on the access of new technology and knowledge but also to create a connection with students while large corporations benefit more by scouting and recruiting talented graduates (Sharpe \& Belz, 2016). These customer needs are aligned with how effectively the university creates knowledge in order to manage the technology it acquires and diffuse its knowledge to students.

According to Osterwalder (2014), the value proposition canvas zooms into the details of the Business Model canvas and is more customer-oriented. It is a tool that integrates with business model canvas and then both of them provide a detailed plan of how to create and sustain value into the organisation and deliver it to the customer.

The value proposition canvas (Fig. 3) consists of the value map and customer profile. The customer profile illustrates what the customer is trying to do ("customerjobs"), what pitfalls and bottlenecks exist during/before/after this task (pains) and the desirable outcome (gains). By observing the customer characteristics, it is easier to describe how the company is planning to create value for the specific customer through the value map. The value map demonstrates how the organisation is going to create value based on the specific customer profile. CET is mainly interacting and cooperating with industrial companies that focus on renewable energy, energy trading and energy storage. Their "customerjobs" related to this potential cooperation are linked to create - improve a product and develop - improve a process in their company. The pains that lead companies to interact with universities are related to lack of knowledge and proper engineering education. The employees may lack training or proper equipment that is required for R\&D, need advice regarding the way they have to approach a problem, how 

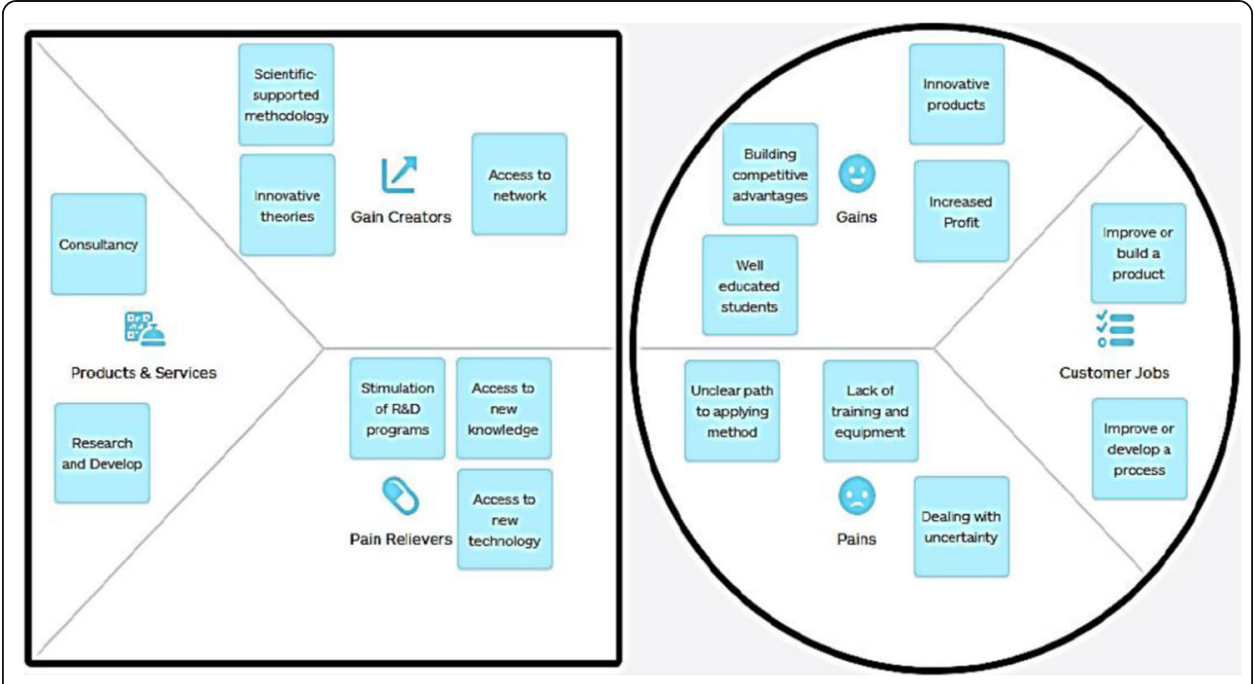

Fig. 3 U-I value proposition Canvas

to solve a technical or design problem or how to deal with the consequences of a malfunction in the company.

Value map illustrates the products the university offers, how these products will deal with the customer pains and in which way they will add profit to the company. University's products, which are based on knowledge diffusion, are directly related to R\&D and consultancy. A collaboration between U-I will stimulate the R\&D sector of the industrial partner by getting access to new knowledge and technology. Furthermore, new knowledge/technology access can support the customer to deal with uncertainty and lack of training by conducting webinars, scientific research, run simulations and get the results it needs in order to further action. Moreover, this collaboration will give access to university's network from which the company can create a connection with researchers for future collaboration or recruit well-educated graduates.

Big data have driven the organisations in the process of extracting and dealing with data seeking patterns and information in general that will add new knowledge in their environment (Khan \& Vorley, 2017; Pillania, 2008). For many years, organisations make use of IT, using various tools that help individuals to enforce knowledge transfer cooperating in order to interact with technology, using technology to establish an interaction between the members of the organisation or linking members. Organisations have established knowledge repositories like catalogue filling systems and databases so individuals can easily access this knowledge. More specifically, databases are very useful because every member of the organisation can have access (Schreiber \& Carley, 2003). This is aligned with what Fengjie, Fei, and Xin (2004) explain in their work. They refer to the organisation as the preferable place to store knowledge. Knowledge must somehow be stored in organisation so that every member has access. Knowledge that is stored explicitly can be found in databases with the form of simple tables (relational databases) or semi-structured text (Preece, Flett, Sleeman, et al., 2001). Organisation's success is highly connected with IT and the effectiveness of its system is aligned with its design and development process (Currim \& Ram, 2012; Tunstall-Pedoe, 2006). IT supports the development of knowledge management in an organisation. Several 
software applications have been created over the years for the specific use besides supporting the organisation's information systems need. Data processing, data storage and communication technologies are facilitating knowledge management. It makes use of databases and data warehouse in order to store and process data/information and also, enterprise resource planning systems. In the era of Big Data, the storage and process of data/information have been increased sharply due to the rapid progress of IT and as a result, the manipulation of them is easier to develop.

According to Nonaka and Takeuchi (1995), "Reconfiguration of existing information through sorting, adding, combining, and categorizing of explicit knowledge (as conducted in computer databases) can lead to new knowledge". Combination, the third step in SECI model is also significantly reinforced by using technologies, such as databases (Fig. 4), that are related with knowledge discovery system (Becerra-Fernandez, 2010) knowledge (as conducted in computer databases) can lead to new knowledge".

The design of databases is a three-step process: The conceptual, logical and physical design part. At first, it will be illustrated the conceptual part of a database in which Aarhus University will store information about the researchers at CET, the projects that every researcher is involved with and information about the companies that the University cooperates or has cooperated in the past. According to Casanova, Breitman, Brauner, and Marins (2007), "A database conceptual schema is a high-level description of how database concepts are organised, which is typical as classes of objects and their attributes". The conceptual part of the database design attempts to schematically illustrate the operations and the relations of interest, is more user-friendly and do not depend on the schema that is going to be used by the Database Management System (Genero, Piattini, \& Calero, 2001; Hawkins, Young, Hubert, \& Hallock, 2001).

The illustration of the conceptual part will be developed using Entity Relationship (ER) diagram in which is visualised the relation between tables with the help of flowcharts. An Entity Relationship diagram consists of entities, correlations between them

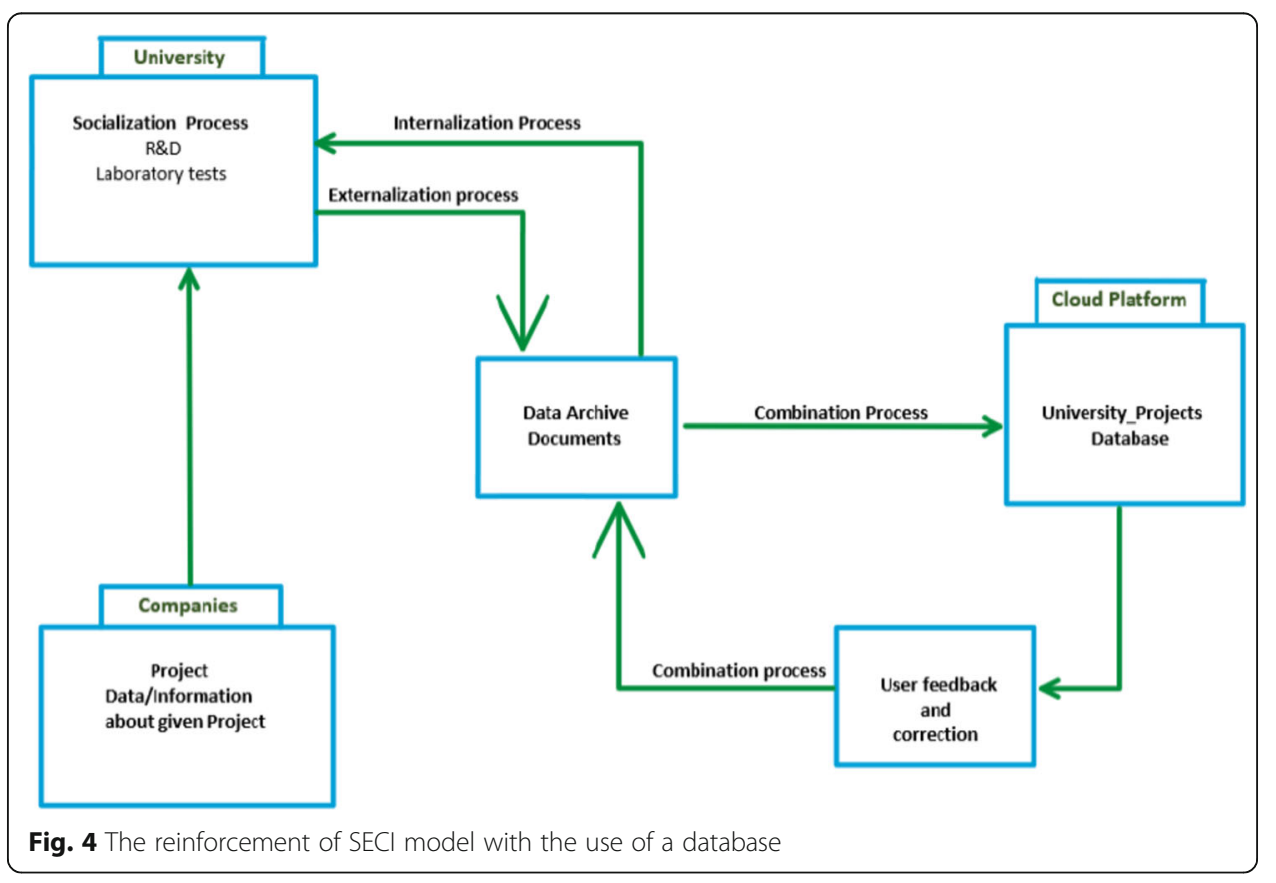


and attributes. These different components are a set of data and relations that will be stored in the database. The cost and complexity of the database development is significantly increased by the number of entities, correlations and attributes (Zhao, Tan, \& Zhang, 2003).

The purpose of this database is to give access to CET members the information related to the projects, previous cooperation with industrial companies that will work towards knowledge creation and transfer.

CET consists of researchers, which will interact with the company in order to develop a potential project. Researchers have a last name, first name and an identity card (ID). A researcher can be Professor, Associate professor, Assistant professor, postdoctoral researcher and PhD student. Personal information of the researchers like phone number, email and date of birth are unnecessary elements because they already exist in another database of the university and are not aligned with the orientation of this database. It is important to mention that the communicating language of the researcher has to be specified, which is crucial, especially in the early stages of the project where both partners are trying to establish a proper relationship. Project has a project name, project ID, a description, a starting date and finish date. The starting/finish date gives information to the user about the duration of the project which can be a piece of useful information because researchers can compare similar projects that their duration varies and evaluate why this happened. Companies have a name, location, phone number and email address (Fig. 5).

The physical design and writing of the database was developed with the Relational Database Management System MySQLworkbench 6.3 (Fig. 6). The University_Projects database will be populated with data that will be acquired from CET department and include:

- Researcher's first and last name,

- languages he/she speaks,

- when he/she joined and left/completed the project,

- the project's name and project's description.

- starting and finishing date of the project.

- the company's name, e-mail address, phone number and physical location.

University Projects is a relational database that is consisted of 8 tables. Tables have identifiers as primary keys that have the suffix id and they have a yellow question mark on the left. For example, idResearcher refers to a unique researcher. The attributes that contain a blue rhombus cannot be null, which means that they necessarily require a value.

\section{Conclusion}

The main purpose of this work was the development of an online database that CET of Aarhus University will use in the future aiming at being more efficient in knowledge sharing with the industry. The development of a database related to the projects and the companies that are connected with the university gives the ability to store information that will be accessible for future research by individuals in the organisation that did not take part to the projects during their implementation phase. It was developed 


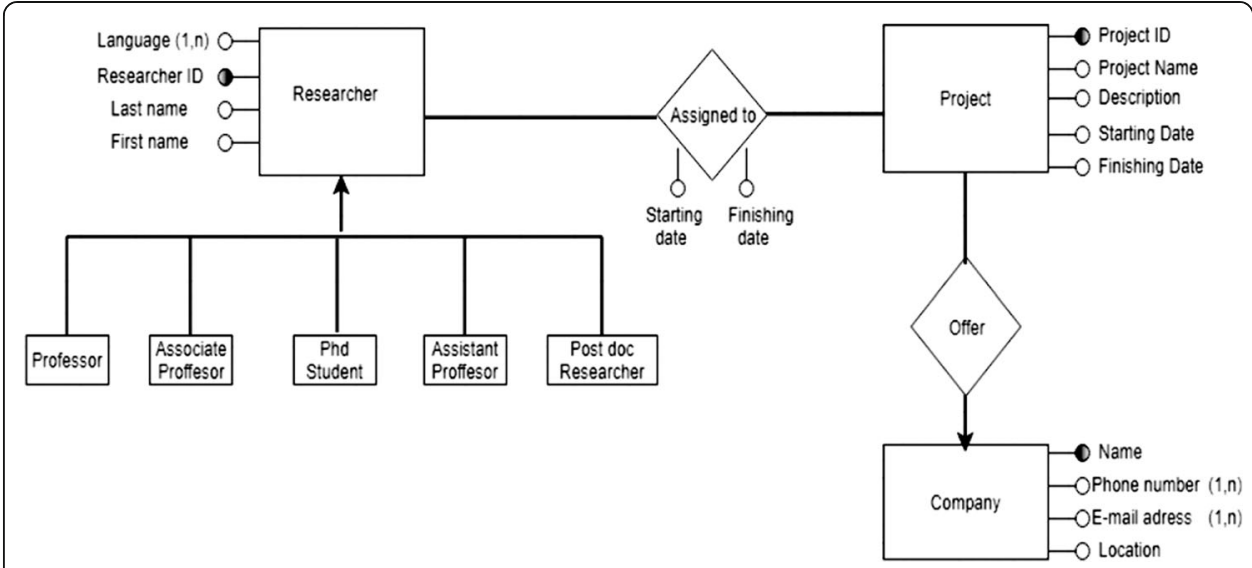

Fig. 5 The Entity-Relationship Diagram using Visual paradigm database online design tool

with the Relational Database Management System MySQLworkbench focusing at being simple granting easy access to all members at the centre regardless their IT literacy levels. A significant effort that works as a leverage of the organisational knowledge is the use of IT. Databases and Information and communications technology (ICT) systems work also as a technical infrastructure of the U-I cooperation because they improve the communication between the two organisations and as a result, improve the inter-organisational knowledge diffusion.

Furthermore, an examination of the cooperation between U-I by locating the bottlenecks in this relationship already mentioned in the literature - and what are the potential benefits for each of them - was conducted. In most cases, the industry seeks the external knowledge, the problem-solving capabilities and the engineering education

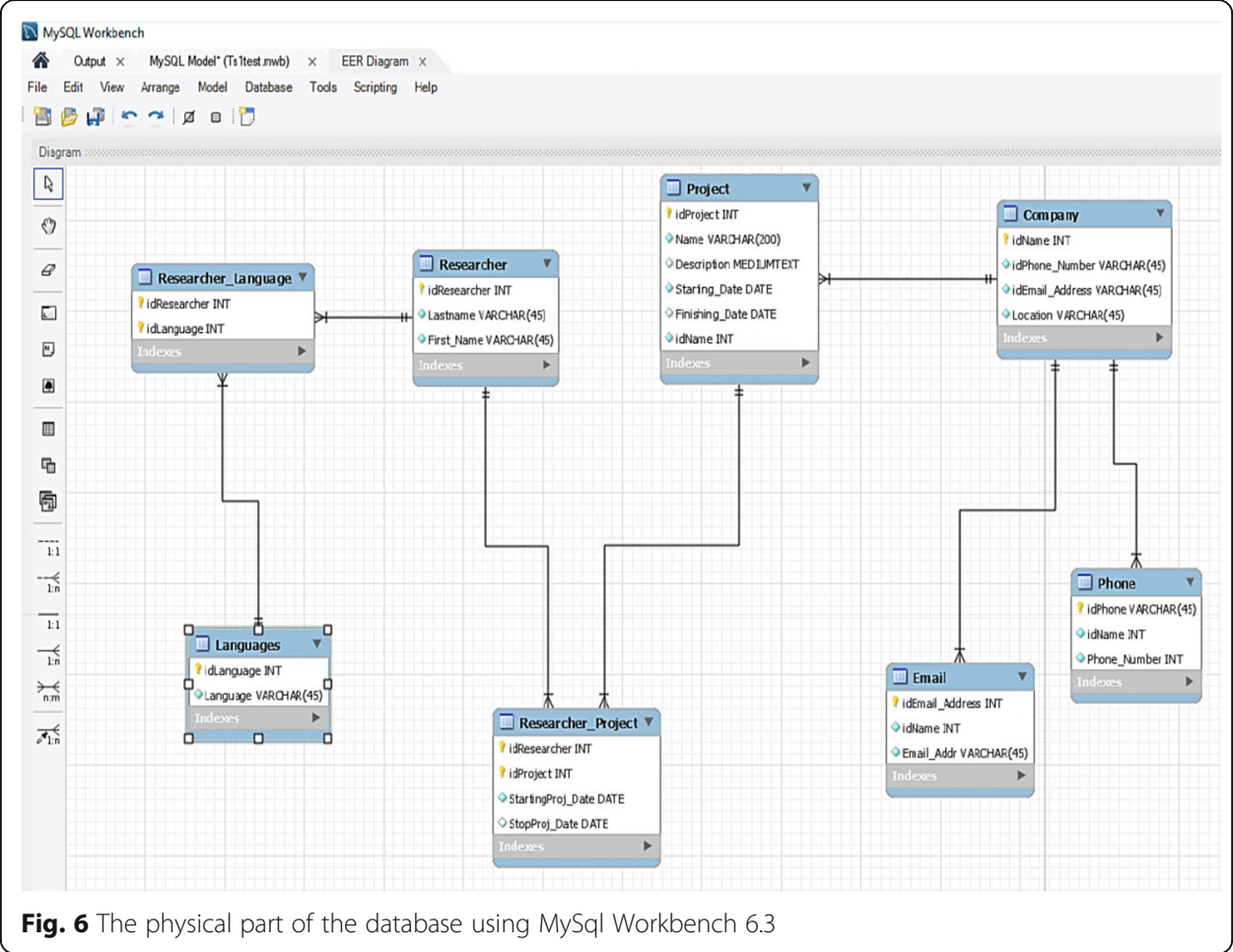


that the University offers. This has to do not only with the innovative products or research done at the university, but also with connections, links with other scientific fields and opportunities for scientific excellence in connection with other sectors, which inevitably could lead to market share growth for the industry. The motivations of the companies for potential cooperation are directly connected with how effectively the university makes use of knowledge management. The Business Model Canvas and the Value Proposition Canvas were used in order to demonstrate the way the University will make use of the knowledge it creates and the important link between knowledge creation and value proposition. The SECI model illustrated in four steps how the knowledge is created and transferred in the organisation while the Value Proposition Canvas makes use of the Value Map and the Customer Profile in order to model the way this knowledge has to be channelled outside of the organisation creating value and relieving the pain of the customer's organisation in order to create a fit and establish a profitable cooperation. The fit between these organisations is achieved when the Industrial companies are interested in the university's value proposition.

A limitation to this paper is that is based on the use of IT as a technical infrastructure of the collaboration between U-I without taking into consideration the perceptions of the individuals in the organisation regarding the use of the database. Furthermore, the SECI Model is based on Japanese organisations, where the employers have built strong relationships due to the larger amount of time spending together in contrast to the university's employees - which spend more time working distantly and in an online environment - and as a result, the most difficult part of the SECI model, the socialisation process, is effectively developed. A question worth answering is in what extend the IT is affecting the knowledge sharing process in the university and how these factors that enhance (or slowing down) the process can effectively be identified and measured.

Abbreviations

CET: Centre for Energy Technologies; ER: Entity Relationship; ICT: Information and communications technology; IT: Information Technology; ID: Identity card; R\&D: Research and Development; SECI: Socialisation, Externalisation, Combination, and Internalisation; SME: Small and medium-sized enterprise; U-I: University-Industry

\section{Acknowledgements}

This study was carried out in collaboration with the Centre for Energy Technologies and therefore great thanks go to all the employees that have been involved in this study.

\section{Authors' contributions}

Conceptualization, E.T.; methodology, E.T. and G.X.; validation, P.E. and G.X. investigation, E.T.; data curation, E.T.; writing—original draft preparation, E.T.; writing—review and editing, P.E. and G.X.; visualization, E.T. and G.X.; supervision, G.X. and P.E. The authors read and approved the final manuscript.

Funding

This research received no specific grant from any funding agency in the public, commercial, or not-for-profit sectors.

Availability of data and materials

All data, materials, and code generated or used during the study appear in the submitted article.

Competing interests

The authors declare that they have no conflict of interest.

Received: 25 April 2020 Accepted: 23 July 2020

Published online: 06 August 2020

References

Amesse, F., \& Cohendet, P. (2001). Transfer revisited from the perspective of the knowledge-based economy. Research Policy, 30(9), 1459-1478.

Anatan, L. (2018). An institutional perspective of knowledge transfer within university and industry alliance. International Journal of Economic Policy in Emerging Economies, 11(4), 378-395. 
Barnes, T., Pashby, I., \& Gibbons, A. (2002). Effective University - Industry interaction: A multi-case evaluation of Collaborative R\&D Projects. European Management Journal, 20(3), 272-285.

Becerra-Fernandez, I. Sabherwal, R. (N.Y.) Arrnonk (Ed.) (2010). Knowledge management: Systems and processes. London M. E. Sharpe

Burnside, B., Witkin, L., \& Forging successful university-industry collaborations (2008). Research. Technology Management, 51 (2), $26-30$.

Casanova, M. A., Breitman, K. K., Brauner, D. F., \& Marins, A. L. A. (2007). Database conceptual schema matching. Computer, 40(10), 102-104.

Castelfranchi, C. (2004). Trust mediation in knowledge management and sharing. Lecture Notes in Computer Science (including subseries Lecture Notes in Artificial Intelligence and Lecture Notes in Bioinformatics), 2995, 304-318.

Chatterjee, S. (2014). Managing constraints and removing obstacles to knowledge management. Journal of Knowledge Management, 12(4), 24-38.

Cohen, W. M., Nelson, R. R., \& Walsh, J. P. (2002). Links and impacts: The influence of public research on Industrial R\&D. Management Science, 48(1), 1-23.

Currim, F., \& Ram, S. (2012). Modeling spatial and temporal set-based constraints during conceptual database design. Information Systems Research, 23(1), 109-128.

Czarnitzki, D., Grimpe, C., \& Pellens, M. (2015). Access to research inputs: Open science versus the entrepreneurial university. Journal of Technology Transfer, 40(6), 1050-1063.

Daft, R., \& Weick, K. E. (1984). Toward a model of organisations interpretive systems. The Academy of Management Review, 9, 284-295.

Dang, Q.; Jasovska, P; Gulzar Rammal, H; Schlenker, K., (2019) Formal-informal channels of university-industry knowledge transfer: The case of Australian business schools, Knowledge Management Research \& Practice, DOl: https://doi.org/10. 1080/14778238.2019.1589395, in press

Dasgupta, P. A., \& Paul, D. A. (1994). Toward a new economics of science. Research Policy, 23(5), 487-521.

Edmondson, G., Valigra, L., Kenward, M., Hudson, L. R., \& Belfield, H. (2012). Making Industry-University partnerships work: Lessons from successful collaborations Science I Business Innovation Board AISBL.

Etzkowitz, H., \& Leydesdorff, L., (2000). The dynamics of innovation: From National Systems and "mode 2" to a Triple Helix of university-industry-government relations. Research Policy, 29(2), 109-123.

Fengjie, A., Fei, Q., \& Xin, C. (2004). Knowledge sharing and web-based knowledge-sharing platform. In Proceedings of the IEEE international conference on E-commerce Technology for Dynamic E-business, CEC-east 2004, (pp. 278-281).

Galbraith, J. (1977). Organisation design. Addison-Wesley. Reading.

Genero, M., Piattini, M., \& Calero, C. (2001). Assurance of Conceptual Data Model Quality Based on early measures, proceedings - 2nd Asia-Pacific conference on quality software. APAQS 2001, 990007, 97-103.

Gilbert, M., \& Cordey-Hayes, M. (1996). Understanding the process of knowledge transfer to achieve successful technological innovation, 1996. Technovation, 16(6), 301-312.

Hadăr, A., Marin, A., Costoiu, M., Boanță, L., (2016). Financial and swot analysis for a pilot model of a TTO from renitt. Romanian Review Precision Mechanics, Optics and Mechatronics, 2016(50), 72-79.

Han, J. (2017). Technology commercialization through sustainable knowledge sharing from university-industry collaborations, with a focus on patent propensity. Sustainability (Switzerland), 9(10), 1808

Hawkins, H. H., Young, S. K., Hubert, K. C., \& Hallock, P. (2001). Conceptual database for understanding and developing information management application. Radiographics: a review publication of the Radiological Society of North America, Inc, 21(3), 781-787.

Hermans, J., \& Castiaux, A. (2006). Knowledge creation through university industry collaborative projects. In Proceedings of the European conference on knowledge management, ECKM, (pp. 233-240).

Howells, J. (1995). A socio-cognitive approach to innovation. Research Policy, 24(6), 883-894.

Jørgensen, L. D., Tambo, T., \& Xydis, G. (2019). An efficiency evaluation of radar-based obstruction lights controlling at a wind turbine test site. Wind Energy, 22(4), 576-586.

Kauppila, O., Mursula, A., Harkonen, J., \& Kujala, J. (2015). Evaluating university-industry collaboration: The European Foundation of quality management excellence model-based evaluation of university-industry collaboration. Tertiary Education and Management, 21(3), 229-244.

Khan, Z., \& Vorley, T. (2017). Big data text analytics: An enabler of knowledge management. Journal of Knowledge Management, 21(1), 18-34.

Killingsworth, B., Xue, Y., \& Liu, Y. (2016). Factors influencing knowledge sharing among global virtual teams. Team Performance Management, 22(5-6), 284-300.

Knudsen, M. P. (2007). The relative importance of interfirm relationships and knowledge transfer for new product development success. Journal of Product Innovation Management, 24(2), 117-138.

Koedinger, K. R., Corbett, A. T., \& Perfetti, C. (2012). The knowledge-learning-instruction framework: Bridging the sciencepractice chasm to enhance robust student learning. Cognitive Science, 36(5), 757-798.

Koscis, G., \& Xydis, G. (2019). Repair process analysis for wind turbines equipped with hydraulic pitch mechanism on the U.S. market in focus of cost optimization. Applied Sciences, 9, 3230. https://doi.org/10.3390/app9163230.

Kukko, M., \& Helander, N. (2012). Knowledge sharing barriers in growing software companies. In Proceedings of the annual Hawaii international conference on system sciences, 6149351, (pp. 3756-3765).

Kumaraswamy, K. S. N., Chitale, C. M., \& Collaborative knowledge sharing strategy to enhance organizational learning (2012). Journal of. Management Development, 31(3), 308-322.

Lee, H.F., Miozzo, M., \& Which types of knowledge-intensive business services firms collaborate with universities for innovation? (2019). Research. Policy, 48(7), 1633-1646.

Lee, Y. S. (2000). The sustainability of university-industry research collaboration: An empirical assessment. Journal of Technology Transfer, 25(2), 111-133.

Lerro, A., lacobone, F. A. \& Schiuma, G. (2012). Knowledge assets assessment strategies: Organizational value, processes, approaches and evaluation architectures. Journal of Knowledge Management, 16(4), 563-575.

Levy, R., Roux, P., \& Wolff, S. (2007). An analysis of science-industry collaborative patterns in a large European University. Journal of Technology Transfer, 34(1), 1-23. 
Lynn, L.H., Reddy, N.M., \& Aram, J.D., (1996). Linking technology and institutions: The innovation community framework. Research Policy, 25(1), 91-106.

Moustaghfir, K., Schiuma, G., Moustaghfir, K., Schiuma, G., \& Schiuma, G. (2013). Knowledge, learning, and innovation: Research and perspectives. Journal of Knowledge Management, 17(4), 495-510.

Nielsen, C., \& Sort, J. (2013). Value exchange in university-industry collaborations. International Journal of Technology Transfer and Commercialisation, 12, 193-215.

Nonaka, I., \& Konno, N. (1998). The concept of "Ba": Building a foundation for knowledge creation. California Management Review, 3, 40-54.

Nonaka, l., \& Takeuchi, H. (1995). The knowledge creating company: How Japanese companies create the dynamics of innovation. New York: Oxford University Press.

Nonaka, l., Takeuchi, H., \& Umemoto, K. (1996). A theory of organizational knowledge creation. International Journal of Technology Management, 11(7-8), 833-845.

Nychis, G., Sekar, V., Andersen, D. G., Kim, H., \& Zhang, H. (2008). An empirical evaluation of entropy-based traffic anomaly detection. In Proceedings of the ACM SIGCOMM internet measurement conference, IMC, (pp. 151-156).

Oliver, A. L., Montgomery, K., \& Barda, S. (2019). The multi-level process of trust and learning in university-industry innovation collaborations. Journal of Technology Transfer 45(3), 758-779.

Osterwalder, A. P. (2010). Business model generation: A handbook for visionaries, game changers, and challengers. New Jersey: Wiley.

Osterwalder, A. P. (2014). Value proposition design. Hoboken: Wiley.

Papadopoulou, K., Alasis, C., \& Xydis, G. (2019). On the wind Blade's surface roughness due to dust accumulation and its impact on the wind Turbine's performance: A heuristic QBlade-based modelling assessment. Environmental Progress \& Sustainable Energy https://doi.org/10.1002/ep.13296, Early View.

Pillania, R. (2008). Innovations and knowledge management in emerging markets. Knowledge and Process Management, 15(3), 184-185.

Preece, A., Flett, A., Sleeman, D., .. Perry, P. (2001). Better knowledge management through knowledge engineering. IEEE Intelligent Systems, 16(1), 36-43.

Riege, A. (2005). Three-dozen knowledge-sharing barriers managers must consider. Journal of Knowledge Management, 9(3), $18-35$.

Robertson, J., McCarthy, I. P., \& Pitt, L. (2019). Leveraging social capital in university-industry knowledge transfer strategies: A comparative positioning framework. Knowledge Management Research and Practice 17(4), 461-472.

Rosenberg, N., \& Nelson, R. R. (1994). American universities and technical advances in industry. Research Policy, 23(3), 323-348.

Saide, S., Indrajit, R. E., Trialih, R., Ramadhani, S., \& Najamuddin, N. (2019). A theoretical and empirical validation of information technology and path-goal leadership on knowledge creation in university: Leaders support and social media trend. Journal of science and technology policy management 10(3), 551-568.

Schiuma, G., \& Carlucci, D. (2018). Managing strategic partnerships with universities in innovation ecosystems: A research agenda. Journal of Open Innovation: Technology, Market, and Complexity, 4(3), 25.

Schreiber, C., \& Carley, K. (2003). The impact of databases on knowledge transfer: Simulation providing theory. Pittsburgh: NAAC SOS Conference Proceedings.

Secundo, G., Del Vecchio, P., Schiuma, G., Passiante, G., \& Activating entrepreneurial learning processes for transforming university students' idea into entrepreneurial practices (2017). International. Journal of Entrepreneurial Behaviour and Research, 23(3), 465-485.

Secundo, G., Dumay, J., Schiuma, G., \& Passiante, G. (2016). Managing intellectual capital through a collective intelligence approach: An integrated framework for universities. Journal of Intellectual Capital, 17(2), 298-319.

Sharpe, M. E., \& Belz, A. (2016). Trends in industry-university relationships.

Thomas, A.; Paul, J.; (2019) Knowledge transfer and innovation through university-industry partnership: An integrated theoretical view, Knowledge Management Research and Practice, DOl: https://doi.org/10.1080/14778238.2018.1552485, in press

Tourangeau, R. (2018). Confidentiality, privacy, and anonymity. In D. Vannette, \& J. Krosnick (Eds.), The Palgrave handbook of survey research. Cham: Palgrave Macmillan. https://doi.org/10.1007/978-3-319-54395-6_58.

Tunstall-Pedoe, W. (2006). United States of America patent no. 7013308.

Xu, G., Zhou, Y., Xu, L., \& Li, S. (2014). Effects of control in open innovation: An empirical study of university-industry cooperation in China. International Journal of Technology, Policy and Management, 14(4), 346-363.

Xydis, G., \& Mihet-Popa, L. (2017). Wind energy integration via residential appliances. Energy Efficiency, 10(2), 319-329. https:// doi.org/10.1007/s12053-016-9459-2.

Xydis, G., Pechlivanoglou, G., \& Nayeri, N. C. (2015). Wind turbine waste heat recovery-A short-term heat loss forecasting approach. Challenges, 6, 188-201. https://doi.org/10.3390/challe6020188.

Yusuf, S. (2008). Intermediating knowledge exchange between universities and businesses. Research Policy, 37(8), 1167-1174.

Zhang, Z. (2017). Graph databases for knowledge management. IT professional, 19(6) 8123475, $26-32$.

Zhao, Y., Tan, H. B. K., \& Zhang, W. (2003). Software cost estimation through conceptual requirement. In Proceedings international conference on quality software, 1319096, (pp. 141-144).

\section{Publisher's Note}

Springer Nature remains neutral with regard to jurisdictional claims in published maps and institutional affiliations. 